\title{
Exploring the biomass-derived chemical space emerging from natural dihydrochalcones through the single-step hemisynthesis of antibacterial balsacones
}

Jérôme Alsarraf,* Jean-François Bilodeau, Jean Legault, François Simard and André Pichette*

${ }^{a}$ Centre de recherche sur la boréalie (CREB), Laboratoire d'analyse et de séparation des essences végétales (LASEVE), Département des Sciences

Fondamentales, Université du Québec à Chicoutimi, 555 boulevard de l'Université, Chicoutimi (Québec), Canada, G7H 2B1.

\section{Table of contents}

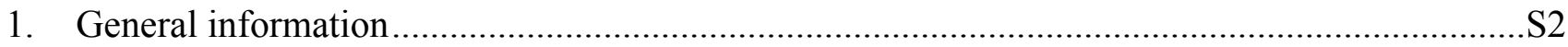

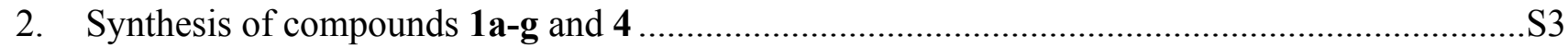

a. General procedure for the Friedel-Crafts alkylation of dihydrochalcones ..............................S3

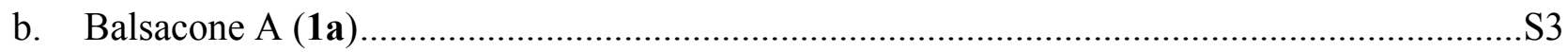

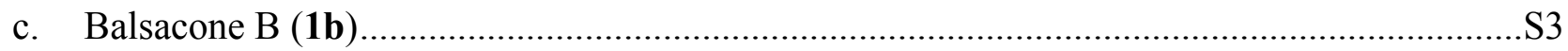

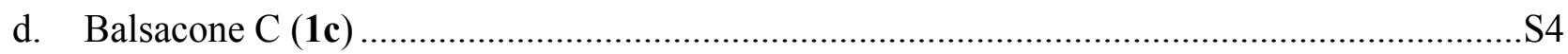

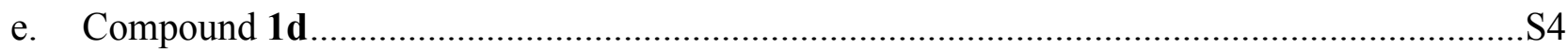

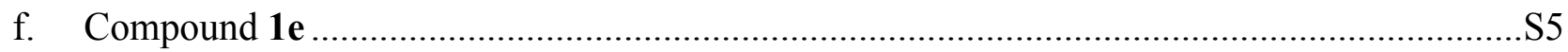

g. Compound 1f

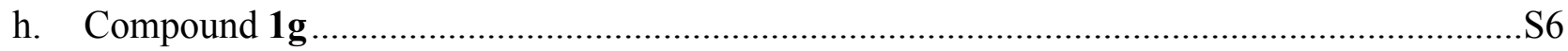

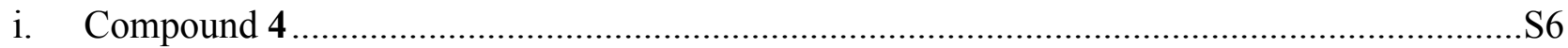

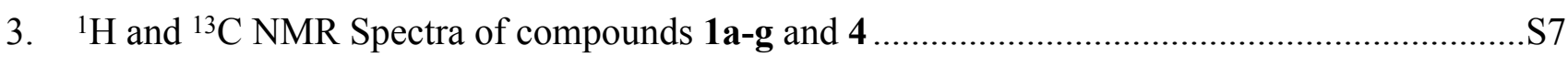

21 pages

15 figures

0 tables

Corresponding authors: jerome1_alsarraf@uqac.ca, +1 4185455011 ext. 2273 (J. Alsarraf) andre pichette@uqac.ca, +1 4185455011 ext. 5081 (A. Pichette) 


\section{General information}

Unless otherwise noted, all starting materials and solvents were purchased from commercial sources and used as received without further purification. Reactions were conducted under argon atmosphere, using anhydrous solvent, unless otherwise noted. All reaction where monitored by thin-layer chromatography (TLC) using normal phase silica gel $60 \mathrm{~F}_{254} 0.25 \mathrm{~mm}$ or reverse phase silica gel $60 \mathrm{RP}-18 \mathrm{~F}_{254} \mathrm{~S} 0.25 \mathrm{~mm}$ precoated aluminum foil plates. Normal phase TLC were visualized under UV (254 $\mathrm{nm})$ or revealed using $\mathrm{H}_{2} \mathrm{SO}_{4}$ under UV (365 nm) as for reverse phase TLC. Flash chromatographic purifications were performed using normal phase silica gel $60(15-40 \mu \mathrm{m})$ or C-18 reverse-phase silica gel (17\%) (40-63 $\mu \mathrm{m})$ columns. NMR spectra were recorded with a Bruker Avance 400 spectrometer at $400 \mathrm{MHz}$ for ${ }^{1} \mathrm{H}$ nuclei and $101 \mathrm{MHz}$ for ${ }^{13} \mathrm{C}$ nuclei, using deuterated acetone or methanol as the solvent. Chemical shifts $\delta$ were reported in ppm relative to the solvent residual peak $\left(\mathrm{CD}_{3} \mathrm{OD} \delta_{\mathrm{H} / \mathrm{C}} 3.31 / 49.00 \mathrm{ppm} ;\left(\mathrm{CD}_{3}\right)_{2} \mathrm{CO}\right.$ $\left.\delta_{\mathrm{H} / \mathrm{C}} 2.05 / 29.84\right)^{1}$ and coupling constants $J$ in Hertz $(\mathrm{Hz})$. Multiplicities were reported using the following abbreviations: s, singlet; d, doublet, t, triplet; q, quartet; m, multiplet; br, broad. HRMS spectra were recorded on an Agilent $6224 \mathrm{MS}$-TOF mass spectrometer equipped with an electrospray source.

Antibacterial assays: activities were evaluated using a modified microdilution method. ${ }^{2}$ Exponentially growing bacteria were plated in 96-well round-bottom microplates at a density of $5 \times 10^{3}$ Gram-negative Escherichia coli (ATCC 25922) or $3.5 \times 10^{4}$ Gram-positive Staphylococcus aureus (ATCC 25923) per well in $100 \mu \mathrm{L}$ of nutrient broth. Increasing concentrations of compounds (solubilized in DMSO, then diluted in nutrient broth or Sabouraud dextrose) were then added (100 $\mu \mathrm{L}$ per well). The final concentration of DMSO in the culture medium was maintained at $0.1 \%$ (volume/volume) to avoid solvent toxicity. The plates were incubated for $24 \mathrm{~h}$ at $37^{\circ} \mathrm{C}$. Absorbance was read using a Varioskan Ascent plate reader (Thermo Electron) at $600 \mathrm{~nm}$. Gentamycin was used as positive control. The results are expressed as the concentration inhibiting $90 \%$ of bacterial growth $\left(\mathrm{MIC}_{90}\right)$.

Cinnamyl alcohols were prepared from the corresponding acids following known procedures. ${ }^{3}$ Dihydrochalcones were isolated from the aerial parts of Kalmia angustifolia or the buds of Populus balsamifera according to reported methods. ${ }^{4}$

\footnotetext{
${ }^{1}$ G. R. Fulmer, A. J. M. Miller, N. H. Sherden, H. E. Gottlieb, A. Nudelman, B. M. Stoltz, J. E. Bercaw and K. I. Goldberg, Organometallics, 2010, 29, 2176-2179.

${ }^{2}$ E. Banfi, G. Scialino and C. Monti-Bragadin, C. J. Antimicrob. Chemother., 2003, 52, 796.

${ }^{3}$ S. Quideau and J. Ralph, J. Agr. Food Chem., 1992, 40, 1108-1110.

${ }^{4}$ S. Lavoie, J. Legault, F. Simard, É. Chiasson and A. Pichette, Tetrahedron Lett., 2013, 54, $1631-1633$.
} 


\section{Synthesis of compounds $\mathbf{1 a - g}$ and 4}

\section{a. General procedure for the Friedel-Crafts alkylation of dihydrochalcones}

To a solution of dihydrochalcone $2(0.35 \mathrm{mmol})$ and allyl alcohol $3(0.087 \mathrm{mmol})$ in acetonitrile $(1.9 \mathrm{~mL})$ was added a solution of 4-toluenesulfonic acid (catalytic loading indicated in Table 2) in acetonitrile ( 0.1 $\mathrm{mL}$ ). The mixture was stirred at room temperature for the time indicated in Table 2. The mixture was then diluted with ethyl acetate $(4 \mathrm{~mL})$, quenched with a saturated aqueous solution of $\mathrm{NaHCO}_{3}(6 \mathrm{~mL})$ and extracted four times with ethyl acetate $(4 \times 15 \mathrm{~mL})$. The organic layers were pooled together, dried over $\mathrm{Na}_{2} \mathrm{SO}_{4}$, filtered and the solvent rotary evaporated. The crude residue was chromatographed over reverse-phase (C-18) silica gel using a gradient of methanol in water (from $50 \%$ to $90 \%$ ) as the mobile phase to afford the expected alkylation product.

\section{b. Balsacone A (1a)}

(E)-1-(2,6-dihydroxy-3-(3-(4-hydroxyphenyl)allyl)-4-methoxyphenyl)-3-(4-hydroxyphenyl)propan-1one

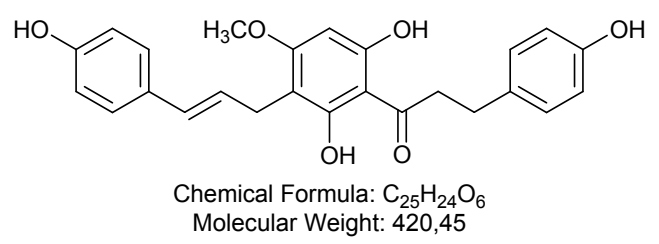

Following the general procedure above, a mixture of 4-hydroxycinnamic alcohol (3a) $(0.0131 \mathrm{~g}, 0.0867$ $\mathrm{mmol})$ and 4,2',6'-trihydroxy-4'-methoxydihydrochalcone (2a) $(0.100 \mathrm{~g}, 0.347 \mathrm{mmol})$ afforded $59 \mathrm{mg}$ of recovered dihydrochalcone $2 \mathbf{a}$ and balsacone $\mathrm{A}(\mathbf{1 a})$ as an off-white powder $(25.5 \mathrm{mg}, 70 \%) . R_{f}=$ $0.34\left(\mathrm{CHCl}_{3} / \mathrm{MeOH} 9: 1\right) ; \mathrm{HRMS}(\mathrm{ESI}) \mathrm{m} / \mathrm{z}$ calcd for $\mathrm{C}_{25} \mathrm{H}_{23} \mathrm{O}_{6}[\mathrm{M}-\mathrm{H}]^{-} 419.1500$, found $419.1505 ;{ }^{1} \mathrm{H}$ NMR (400 MHz, $\left.\left(\mathrm{CD}_{3}\right)_{2} \mathrm{CO}\right): \delta 8.76($ br s, $2 \mathrm{H}), 7.17(\mathrm{~d}, J=8.5 \mathrm{~Hz}, 2 \mathrm{H}), 7.10(\mathrm{~d}, J=8.3 \mathrm{~Hz}, 2 \mathrm{H}), 6.78$ $-6.71(\mathrm{~m}, 4 \mathrm{H}), 6.35-6.26(\mathrm{~m}, 1 \mathrm{H}), 6.16(\mathrm{~s}, 1 \mathrm{H}), 6.11(\mathrm{dt}, J=15.8,6.6 \mathrm{~Hz}, 1 \mathrm{H}), 3.82(\mathrm{~s}, 3 \mathrm{H}), 3.43-$ $3.33(\mathrm{~m}, 4 \mathrm{H}), 2.93-2.85(\mathrm{~m}, 1 \mathrm{H}) ;{ }^{13} \mathrm{C}$ NMR $\left(101 \mathrm{MHz},\left(\mathrm{CD}_{3}\right)_{2} \mathrm{CO}\right): \delta 206.1,164.3,163.7,161.5,157.3$, 156.4, 133.4, 130.5, 130.2, 130.0, 127.9, 126.2, 116.1, 116.0, 107.5, 105.5, 91.3, 56.0, 47.1, 30.6, 26.1 . ${ }^{1} \mathrm{H}$ and ${ }^{13} \mathrm{C}$ NMR spectra were consistent with literature data. ${ }^{4}$

\section{c. Balsacone B (1b)}

(E)-3-(4-methoxyphenyl)-1-(2,4,6-trihydroxy-3-(3-(4-hydroxyphenyl)allyl)phenyl)propan-1-one

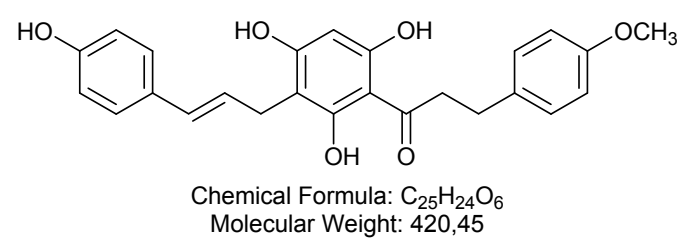

Following the general procedure above, a mixture of 4-hydroxycinnamic alcohol (3a) $(0.0131 \mathrm{~g}, 0.0867$ $\mathrm{mmol})$ and 2',4',6'-trihydroxy-4-methoxydihydrochalcone $(\mathbf{2 b})(0.100 \mathrm{~g}, 0.347 \mathrm{mmol})$ in acetonitrile $(3.9 \mathrm{~mL})$ afforded balsacone B (1b) as an off-white powder (18.7 mg, $51 \%) . R_{f}=0.36\left(\mathrm{CHCl}_{3} / \mathrm{MeOH}\right.$ 
9:1); HRMS (ESI) $\mathrm{m} / \mathrm{z}$ calcd for $\mathrm{C}_{25} \mathrm{H}_{23} \mathrm{O}_{6}[\mathrm{M}-\mathrm{H}]^{-} 419.1500$, found 419.1501; $\mathrm{H}^{1} \mathrm{NMR}(400 \mathrm{MHz}$, $\left.\left(\mathrm{CD}_{3}\right)_{2} \mathrm{CO}\right): \delta 14.0$ (br s, $\left.1 \mathrm{H}\right), 9.13$ (br s, $\left.2 \mathrm{H}\right), 7.18(\mathrm{~d}, J=7.5 \mathrm{~Hz}, 4 \mathrm{H}), 6.83(\mathrm{~d}, J=8.4 \mathrm{~Hz}, 2 \mathrm{H}), 6.74(\mathrm{~d}$, $J=8.4 \mathrm{~Hz}, 2 \mathrm{H}), 6.34$ (br d, $J=15.8 \mathrm{~Hz}, 1 \mathrm{H}), 6.17$ (dt, $J=15.8,6.5 \mathrm{~Hz}, 1 \mathrm{H}), 6.11(\mathrm{~s}, 1 \mathrm{H}), 3.74(\mathrm{~s}, 3 \mathrm{H})$, $3.42(\mathrm{~d}, J=6.4 \mathrm{~Hz}, 2 \mathrm{H}), 3.40-3.32(\mathrm{~m}, 2 \mathrm{H}), 2.97-2.87(\mathrm{~m}, 2 \mathrm{H}) ;{ }^{13} \mathrm{C} \mathrm{NMR}\left(101 \mathrm{MHz},\left(\mathrm{CD}_{3}\right)_{2} \mathrm{CO}\right): \delta$ 205.5, 165.1, 162.8, 160.8, 158.9, 157.3, 134.7, 130.6, 130.2, 130.0, 127.9, 126.3, 116.1, 114.5, 106.5, 105.1, 95.0, 55.4, 46.8, 30.6, 26.2. ${ }^{1} \mathrm{H}$ and ${ }^{13} \mathrm{C}$ NMR spectra were consistent with literature data. ${ }^{4}$

\section{d. Balsacone $C(\mathbf{1 c})$}

(E)-3-phenyl-1-(2,4,6-trihydroxy-3-(3-(4-hydroxyphenyl)allyl)phenyl)propan-1-one

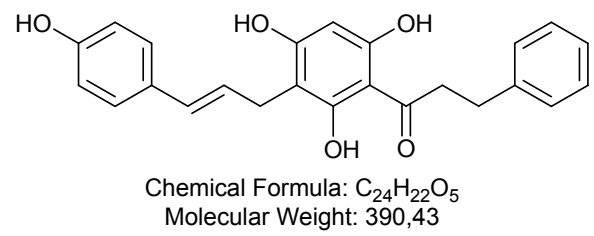

Following the general procedure above, a mixture of 4-hydroxycinnamic alcohol (3a) (0.0131 g, 0.0867 $\mathrm{mmol})$ and 2',4',6'-trihydroxydihydrochalcone $(\mathbf{2 c})(0.0898 \mathrm{~g}, 0.348 \mathrm{mmol})$ in acetonitrile $(4.9 \mathrm{~mL})$ afforded balsacone $\mathrm{C}$ (1c) as an off-white powder (19.0 mg, $56 \%) . R_{f}=0.36\left(\mathrm{CHCl}_{3} / \mathrm{MeOH} 9: 1\right)$; HRMS (ESI) $\mathrm{m} / \mathrm{z}$ calcd for $\mathrm{C}_{24} \mathrm{H}_{21} \mathrm{O}_{5}[\mathrm{M}-\mathrm{H}]^{-} 389.1394$, found 389.1392; $\mathrm{H}^{1} \mathrm{NMR}\left(400 \mathrm{MHz},\left(\mathrm{CD}_{3}\right)_{2} \mathrm{CO}\right): \delta$ $7.31-7.21(\mathrm{~m}, 4 \mathrm{H}), 7.20-7.11(\mathrm{~m}, 3 \mathrm{H}), 6.74(\mathrm{~d}, J=8.6 \mathrm{~Hz}, 2 \mathrm{H}), 6.34(\mathrm{br} \mathrm{d}, J=15.8 \mathrm{~Hz}, 1 \mathrm{H}), 6.18(\mathrm{dt}$, $J=15.7,6.5 \mathrm{~Hz}, 1 \mathrm{H}), 6.11(\mathrm{~s}, 1 \mathrm{H}), 3.48-3.32(\mathrm{~m}, 4 \mathrm{H}), 3.02-2.92(\mathrm{~m}, 2 \mathrm{H}) ;{ }^{13} \mathrm{C} \mathrm{NMR}(101 \mathrm{MHz}$, $\left.\left(\mathrm{CD}_{3}\right)_{2} \mathrm{CO}\right): \delta 205.2,165.1,163.3,161.3,157.2,143.0,130.6,129.9,129.3,129.1,127.9,126.6,126.4$, 116.1, 106.3, 105.0, 95.2, 46.5, 31.5, 26.2. ${ }^{1} \mathrm{H}$ and ${ }^{13} \mathrm{C}$ NMR spectra were consistent with literature data. ${ }^{4}$

\section{e. Compound 1d}

(E)-3-(4-hydroxyphenyl)-1-(2,4,6-trihydroxy-3-(3-(4-hydroxyphenyl)allyl)phenyl) propan-1-one

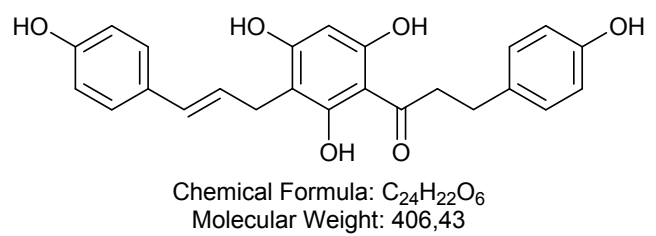

Following the general procedure above, a mixture of 4-hydroxycinnamic alcohol (3a) (0.0133 g, $0.0886 \mathrm{mmol})$ and phloretin $(\mathbf{2 d})(0.0986 \mathrm{~g}, 0.359 \mathrm{mmol})$ afforded the title compound $\mathbf{1 d}$ as a pale-yellow powder (20.8 mg, $57 \%) . R_{f}=0.72\left(\mathrm{CHCl}_{3} / \mathrm{MeOH} 8: 2\right)$; HRMS (ESI) m/z calcd for $\mathrm{C}_{24} \mathrm{H}_{21} \mathrm{O}_{6}[\mathrm{M}-\mathrm{H}]^{-}$ 405.1344, found 405.1351; $\mathrm{H}^{1} \mathrm{NMR}\left(400 \mathrm{MHz},\left(\mathrm{CD}_{3}\right)_{2} \mathrm{CO}\right): \delta 14.03$ (br s, $\left.1 \mathrm{H}\right), 8.75$ (br s, 3H), $7.18(\mathrm{~d}$, $J=8.6 \mathrm{~Hz}, 2 \mathrm{H}), 7.09(\mathrm{~d}, J=8.4 \mathrm{~Hz}, 2 \mathrm{H}), 6.77-6.71(\mathrm{~m}, 4 \mathrm{H}), 6.38-6.29(\mathrm{~m}, 1 \mathrm{H}), 6.16(\mathrm{dt}, J=15.8$, $6.5 \mathrm{~Hz}, 1 \mathrm{H}), 6.10(\mathrm{~s}, 1 \mathrm{H}), 3.42(\mathrm{dd}, J=6.5,1.1 \mathrm{~Hz}, 1 \mathrm{H}), 3.38-3.31(\mathrm{~m}, 2 \mathrm{H}), 2.93-2.84(\mathrm{~m}, 2 \mathrm{H}) ;{ }^{13} \mathrm{C}$ NMR (101 MHz, $\left.\left(\mathrm{CD}_{3}\right)_{2} \mathrm{CO}\right): \delta 205.7,165.1,162.8,160.8,157.3,156.4,133.5,130.6,130.2,130.0$, $127.9,126.3,116.1,116.0,106.5,105.0,95.0,46.9,30.7,26.2$. 


\section{f. Compound 1e}

(E)-1-(2,6-dihydroxy-4-methoxy-3-(3-(4-methoxyphenyl)allyl)phenyl)-3-(4-hydroxyphenyl)propan-1one

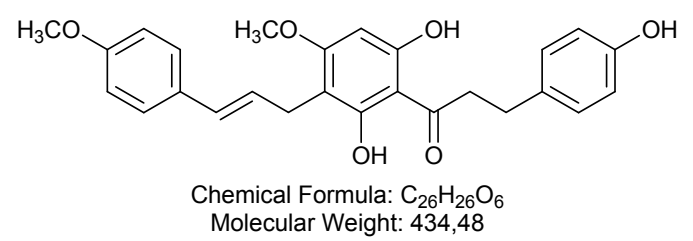

Following the general procedure above, a mixture of 4-methoxycinnamic alcohol (3b) $(0.0145 \mathrm{~g}, 0.0883$ $\mathrm{mmol})$ and 4,2',6'-trihydroxy-4'-methoxydihydrochalcone (2a) $(0.100 \mathrm{~g}, 0.347 \mathrm{mmol})$ afforded the title compound 1e as an off-white powder (24.0 mg, $63 \%) . R_{f}=0.60\left(\mathrm{CHCl}_{3} / \mathrm{MeOH} 9: 1\right) ; \mathrm{HRMS}$ (ESI) $\mathrm{m} / \mathrm{z}$ calcd for $\mathrm{C}_{26} \mathrm{H}_{25} \mathrm{O}_{6}[\mathrm{M}-\mathrm{H}]^{-} 433.1657$, found 433.1634; $\mathrm{H}^{1} \mathrm{NMR}\left(400 \mathrm{MHz},\left(\mathrm{CD}_{3}\right)_{2} \mathrm{CO}\right): \delta 7.26(\mathrm{~d}, J=$ $8.6 \mathrm{~Hz}, 2 \mathrm{H}), 7.10(\mathrm{~d}, J=8.2 \mathrm{~Hz}, 2 \mathrm{H}), 6.82(\mathrm{~d}, J=8.6 \mathrm{~Hz}, 2 \mathrm{H}), 6.75(\mathrm{~d}, J=8.2 \mathrm{~Hz}, 2 \mathrm{H}), 6.33(\mathrm{br} \mathrm{d}, J=$ $15.8 \mathrm{~Hz}, 1 \mathrm{H}), 6.18(\mathrm{~s}, 1 \mathrm{H}), 6.16(\mathrm{dt}, J=13.0,7.0 \mathrm{~Hz}, 1 \mathrm{H}), 3.82(\mathrm{~s}, 3 \mathrm{H}), 3.75(\mathrm{~s}, 3 \mathrm{H}), 3.45-3.35(\mathrm{~m}$, 4H), $2.94-2.86(\mathrm{~m}, 2 \mathrm{H}) ;{ }^{13} \mathrm{C}$ NMR $\left(101 \mathrm{MHz},\left(\mathrm{CD}_{3}\right)_{2} \mathrm{CO}\right): \delta 205.7,164.4,163.8,161.7,159.7,156.4$, 133.4, 131.6, 130.2, 129.8, 127.8, 127.0, 116.0, 114.6, 107.3, 105.5, 91.4, 56.0, 55.4, 47.1, 30.6, 26.1.

\section{g. Compound $1 \mathrm{f}$}

(E)-1-(3-cinnamyl-2,6-dihydroxy-4-methoxyphenyl)-3-(4-hydroxyphenyl)propan-1-one

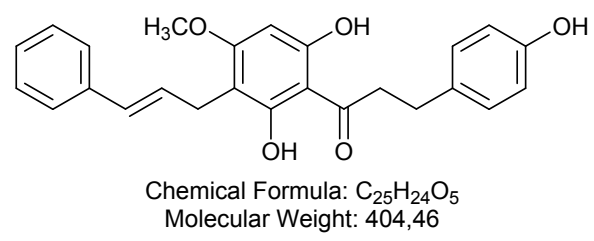

Following the general procedure above, a mixture of cinnamic alcohol (3c) $(0.0132 \mathrm{~g}, 0.0984 \mathrm{mmol})$ and 4,2',6'-trihydroxy-4'-methoxydihydrochalcone (2a) $(0.113 \mathrm{~g}, 0.392 \mathrm{mmol})$ afforded the title compound 1f as an off-white powder (15.9 mg, $40 \%) . R_{f}=0.51\left(\mathrm{CHCl}_{3} / \mathrm{MeOH} 9: 1\right)$; HRMS (ESI) m/z calcd for $\mathrm{C}_{25} \mathrm{H}_{23} \mathrm{O}_{5}[\mathrm{M}-\mathrm{H}]^{-}$403.1551, found 403.1552; $\mathrm{H}^{1} \mathrm{NMR}\left(400 \mathrm{MHz},\left(\mathrm{CD}_{3}\right)_{2} \mathrm{CO}\right): \delta 13.78(\mathrm{br} \mathrm{s}, 1 \mathrm{H}), 9.90$ (br s, 1H), 8.13 (br s, 1H), 7.33 (d, $J=7.2 \mathrm{~Hz}, 2 \mathrm{H}), 7.25$ (t, J = 7.6 Hz, 2H), 7.15 (t, $J=7.2 \mathrm{~Hz}, 1 \mathrm{H}), 7.10$ $(\mathrm{d}, J=8.4 \mathrm{~Hz}, 2 \mathrm{H}), 6.75(\mathrm{~d}, J=8.4 \mathrm{~Hz}, 2 \mathrm{H}), 6.40(\mathrm{br} \mathrm{d}, J=15.9 \mathrm{~Hz}, 1 \mathrm{H}), 6.33(\mathrm{dt}, J=15.9,5.8 \mathrm{~Hz}$, $1 \mathrm{H}), 6.18(\mathrm{~s}, 1 \mathrm{H}), 3.84(\mathrm{~s}, 3 \mathrm{H}), 3.43(\mathrm{~d}, J=5.8 \mathrm{~Hz}, 2 \mathrm{H}), 3.41-3.34(\mathrm{~m}, 2 \mathrm{H}), 2.93-2.86(\mathrm{~m}, 2 \mathrm{H}) ;{ }^{13} \mathrm{C}$ NMR (101 MHz, $\left.\left(\mathrm{CD}_{3}\right)_{2} \mathrm{CO}\right): \delta 205.5,164.4,163.8,161.6,156.4,138.9,133.4,130.3,130.2,129.4,129.3$, 127.5, 126.7, 116.0, 107.1, 105.5, 91.4, 56.0, 47.1, 30.6, 26.2 . 


\section{h. Compound $1 \mathrm{~g}$}

(E)-1-(2,6-dihydroxy-3-(3-(4-hydroxy-3-methoxyphenyl)allyl)-4-methoxyphenyl)-3-(4hydroxyphenyl)propan-1-one

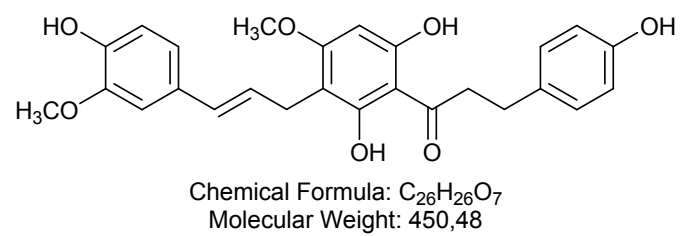

Following the general procedure above, a mixture of coniferyl alcohol (3d) $(0.0158 \mathrm{~g}, 0.0877 \mathrm{mmol})$ and 4,2',6'-trihydroxy-4'-methoxydihydrochalcone (2a) $(0.100 \mathrm{~g}, 0.347 \mathrm{mmol})$ afforded the title compound $1 \mathrm{~g}$ as an off-white powder (18.1 mg, $45 \%) . R_{f}=0.47\left(\mathrm{CHCl}_{3} / \mathrm{MeOH} 9: 1\right)$; HRMS (ESI) m/z calcd for $\mathrm{C}_{26} \mathrm{H}_{25} \mathrm{O}_{7}[\mathrm{M}-\mathrm{H}]^{-} 449.1606$, found 449.1605; $\mathrm{H}^{1} \mathrm{NMR}\left(400 \mathrm{MHz}, \mathrm{CD}_{3} \mathrm{OD}\right): \delta 7.05$ (d, $\left.J=8.3 \mathrm{~Hz}, 2 \mathrm{H}\right)$, $6.86(\mathrm{~d}, J=0.8 \mathrm{~Hz}, 1 \mathrm{H}), 6.74-6.64(\mathrm{~m}, 4 \mathrm{H}), 6.23(\mathrm{br} \mathrm{d}, J=15.7 \mathrm{~Hz}, 1 \mathrm{H}), 6.12-6.01(\mathrm{~m}, 1 \mathrm{H}), 6.04(\mathrm{~s}$, $1 \mathrm{H}), 3.84(\mathrm{~s}, 3 \mathrm{H}), 3.81(\mathrm{~s}, 3 \mathrm{H}), 3.39-3.32(\mathrm{~m}, 4 \mathrm{H}), 2.90-2.83(\mathrm{~m}, 2 \mathrm{H}) ;{ }^{13} \mathrm{C}$ NMR $\left(101 \mathrm{MHz}, \mathrm{CD}_{3} \mathrm{OD}\right)$ : $\delta$ 207.0, 165.0, 164.0, 162.5, 156.5, 148.9, 146.6, 134.0, 131.8, 130.5, 130.3, 126.9, 120.2, 116.1, 116.1, $110.0,107.6,105.8,91.2,56.3,56.0,47.6,31.5,26.3$.

\section{i. Compound 4}

1-(trans-7-hydroxy-2-(4-hydroxy-3-methoxyphenyl)-3-((E)-3-(4-hydroxy-3-methoxyphenyl)allyl)-5methoxychroman-8-yl)-3-(4-hydroxyphenyl)propan-1-one

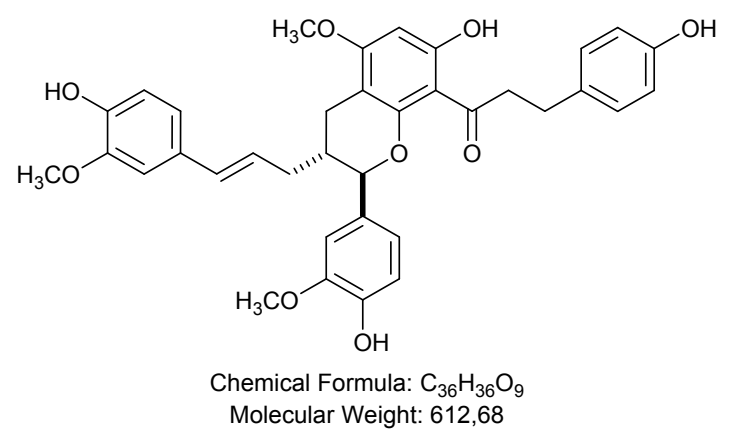

Following the general procedure above, a mixture of coniferyl alcohol (3d) $(0.0158 \mathrm{~g}, 0.0877 \mathrm{mmol})$ and 4,2',6'-trihydroxy-4'-methoxydihydrochalcone (2a) $(0.100 \mathrm{~g}, 0.347 \mathrm{mmol})$ afforded the title compound 4 as an off-white powder (5.5 mg, $21 \%) . R_{f}=0.58\left(\mathrm{CHCl}_{3} / \mathrm{MeOH} 10: 1\right)$; HRMS (ESI) m/z calcd for $\mathrm{C}_{36} \mathrm{H}_{35} \mathrm{O}_{9}[\mathrm{M}-\mathrm{H}]^{-}$611.2287, found 611.2287; $\mathrm{H}^{1} \mathrm{NMR}\left(400 \mathrm{MHz},\left(\mathrm{CD}_{3}\right)_{2} \mathrm{CO}\right): \delta 7.18(\mathrm{~d}, J=1.7 \mathrm{~Hz}$, $1 \mathrm{H}), 7.03-6.97(\mathrm{~m}, 2 \mathrm{H}), 6.92(\mathrm{~d}, J=8.0 \mathrm{~Hz}, 1 \mathrm{H}), 6.81(\mathrm{dd}, \mathrm{J}=8.2,1.7 \mathrm{~Hz}, 1 \mathrm{H}), 6.74(\mathrm{~d}, J=8.1 \mathrm{~Hz}$, $1 \mathrm{H}), 6.61(\mathrm{~s}, 4 \mathrm{H}), 6.29(\mathrm{br} \mathrm{d}, J=15.8 \mathrm{~Hz}, 1 \mathrm{H}), 6.10(\mathrm{~s}, 1 \mathrm{H}), 6.06-5.97(\mathrm{~m}, 1 \mathrm{H}), 4.82(\mathrm{~d}, J=9.2 \mathrm{~Hz}$, $1 \mathrm{H}), 3.87(\mathrm{~s}, 3 \mathrm{H}), 3.84(\mathrm{~s}, 3 \mathrm{H}), 3.77(\mathrm{~s}, 3 \mathrm{H}), 3.25-3.06(\mathrm{~m}, 2 \mathrm{H}), 2.86(\mathrm{dd}, J=15.7,4.2 \mathrm{~Hz}, 1 \mathrm{H}), 2.76-$ 2.68 (m, 2H), $2.40-2.11(\mathrm{~m}, 4 \mathrm{H}) ;{ }^{13} \mathrm{C}$ NMR (101 MHz, $\left.\left(\mathrm{CD}_{3}\right)_{2} \mathrm{CO}\right): \delta 205.6,166.5,164.5,158.3,156.2$, 148.7, 148.4, 147.9, 146.9, 132.9, 132.7, 131.5, 130.6, 129.8, 124.9, 121.7, 120.4, 115.8, 115.7, 115.6, $111.7,109.8,105.9,102.9,92.7,84.5,56.3,56.3,56.2,46.3,37.9 .36 .3,30.4,26.2$. 
3. ${ }^{1} \mathrm{H}$ and ${ }^{13} \mathrm{C}$ NMR Spectra of compounds $\mathbf{1 a - g}$ and 4

a. Figure S1: ${ }^{1} H$ NMR spectrum of balsacone A (1a)

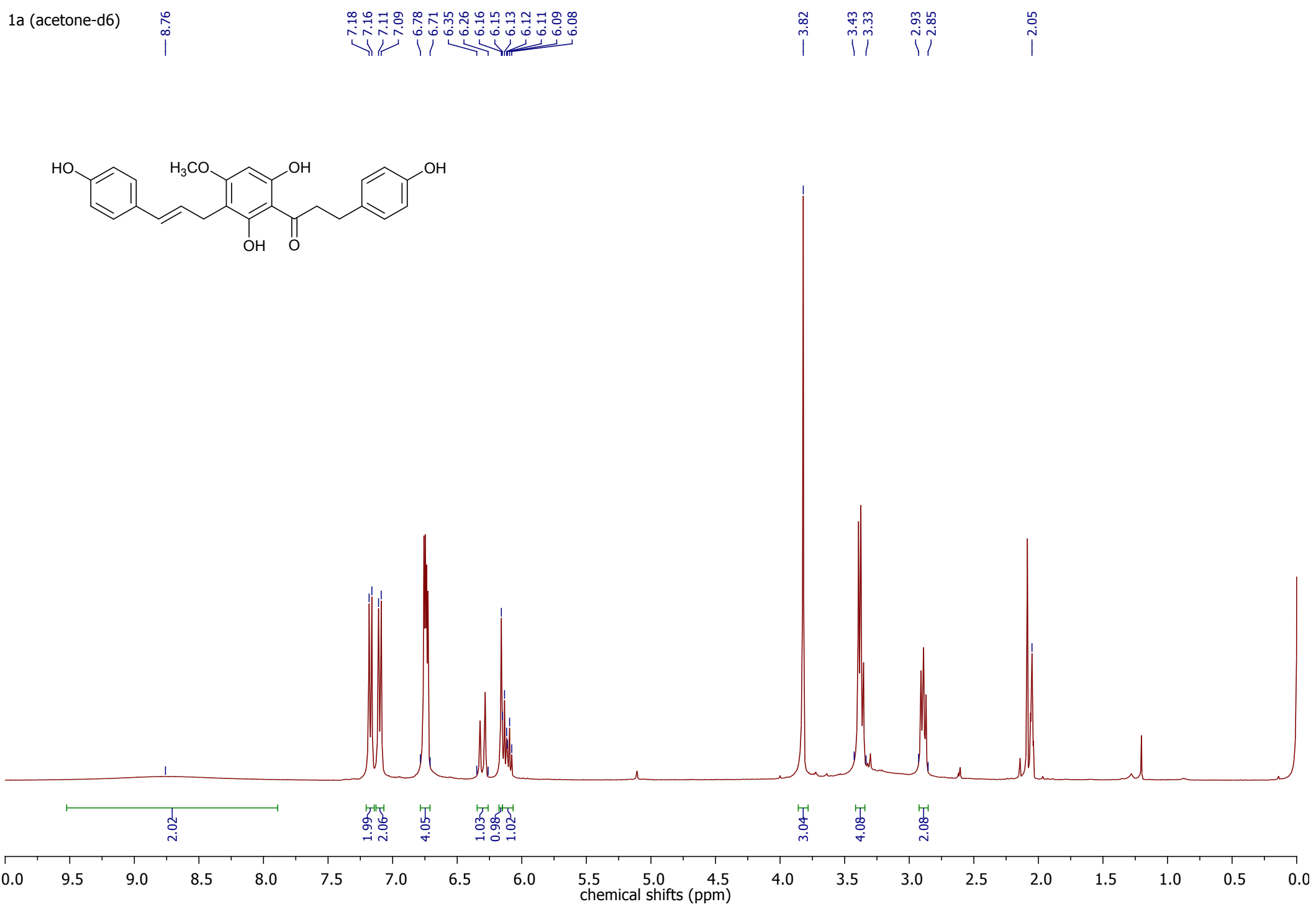


b. Figure S2: ${ }^{1} H$ NMR spectrum of balsacone B (1b)

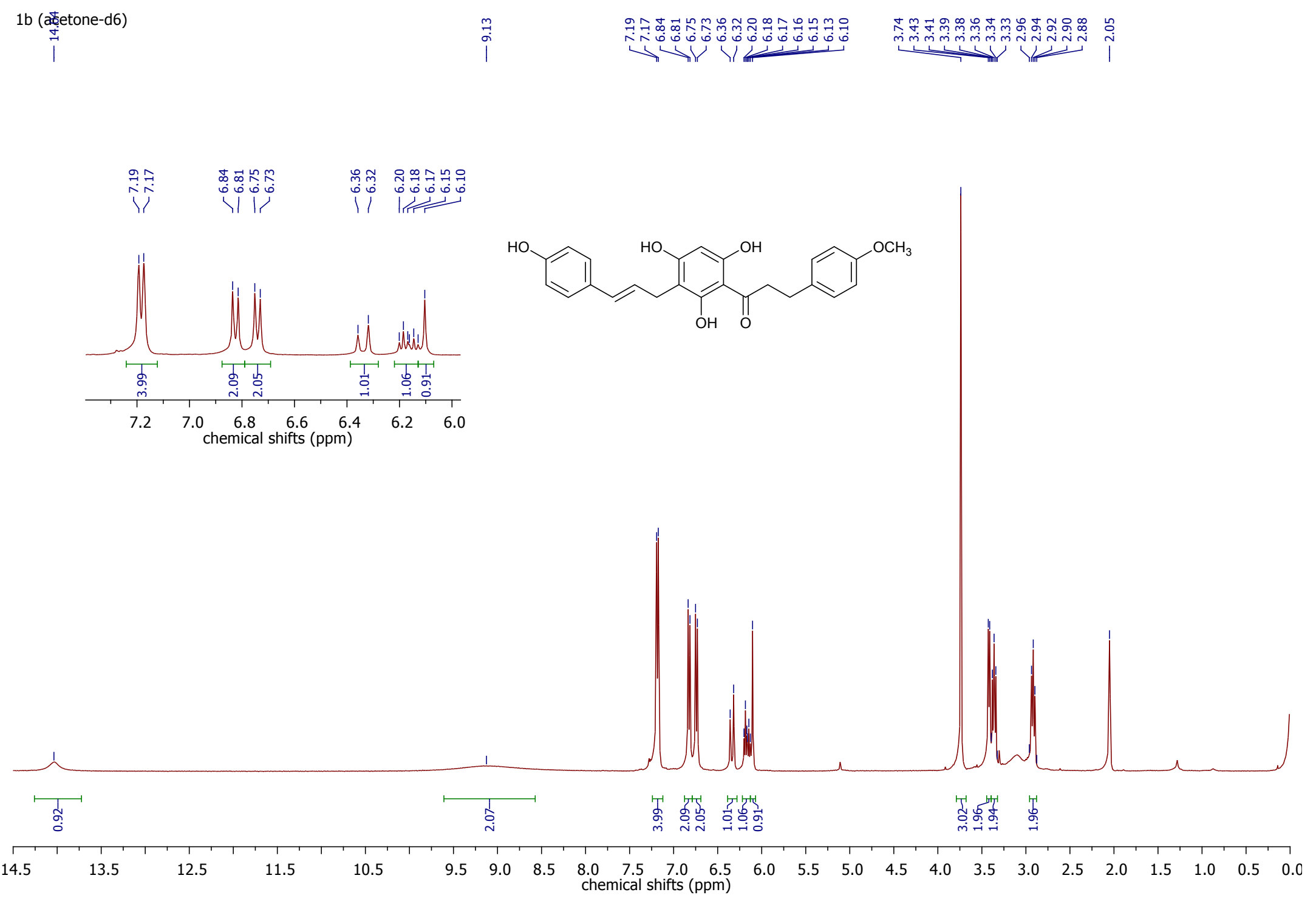


c. Figure S3: ${ }^{13} \mathrm{C}$ NMR spectrum of balsacone B (1b)

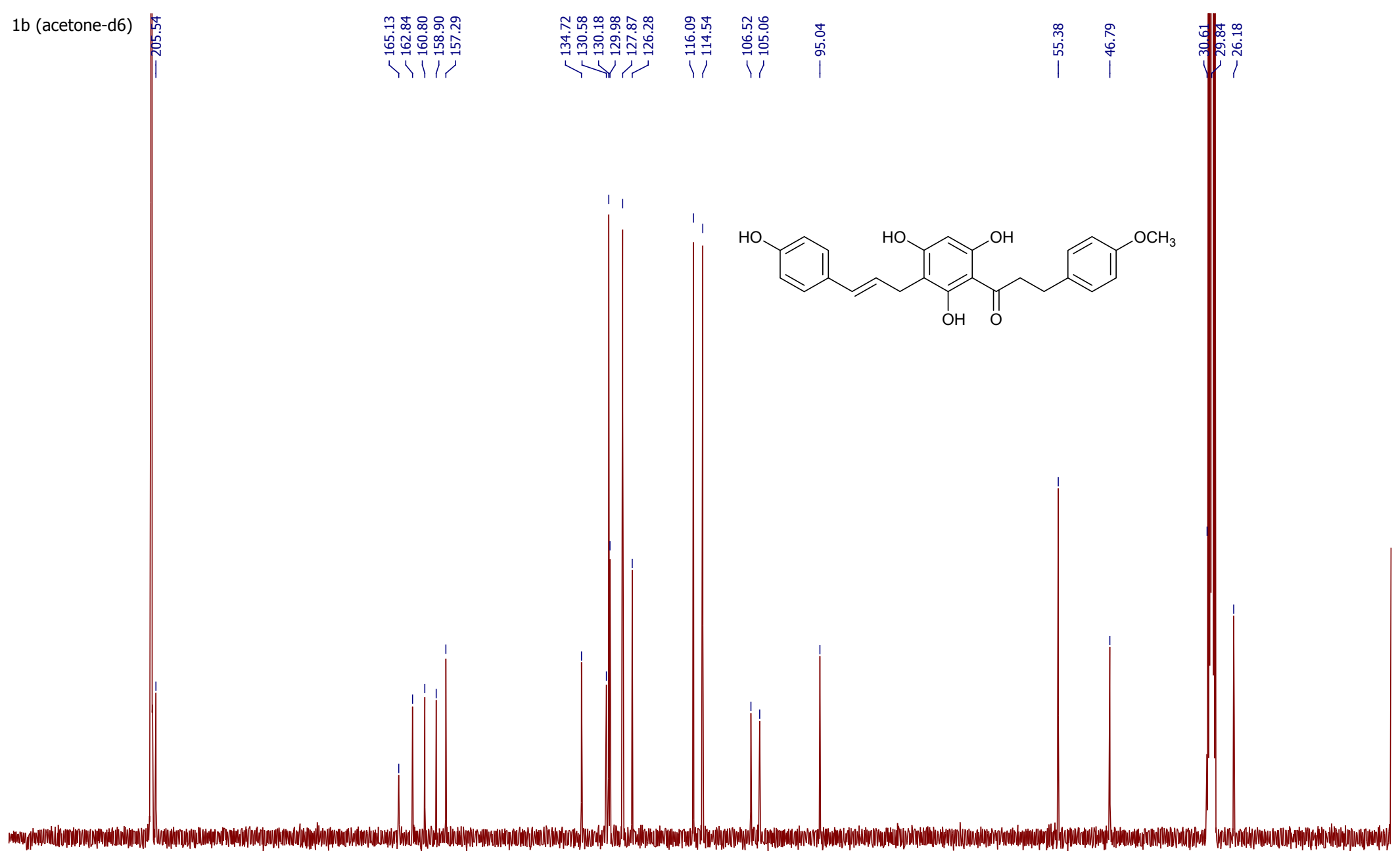

$\begin{array}{lllllllllllllllllllllll}230 & 220 & 210 & 200 & 190 & 180 & 170 & 160 & 150 & 140 & 130 \begin{array}{c}120 \\ \text { chemical shifts (ppm) }\end{array} & 90 & 80 & 70 & 60 & 50 & 40 & 30 & 20 & 10 & 0\end{array}$ 
d. Figure S4: ${ }^{1} H$ NMR spectrum of balsacone C (1c)
1c (acetone-d6)

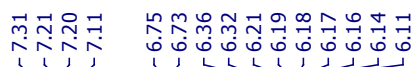
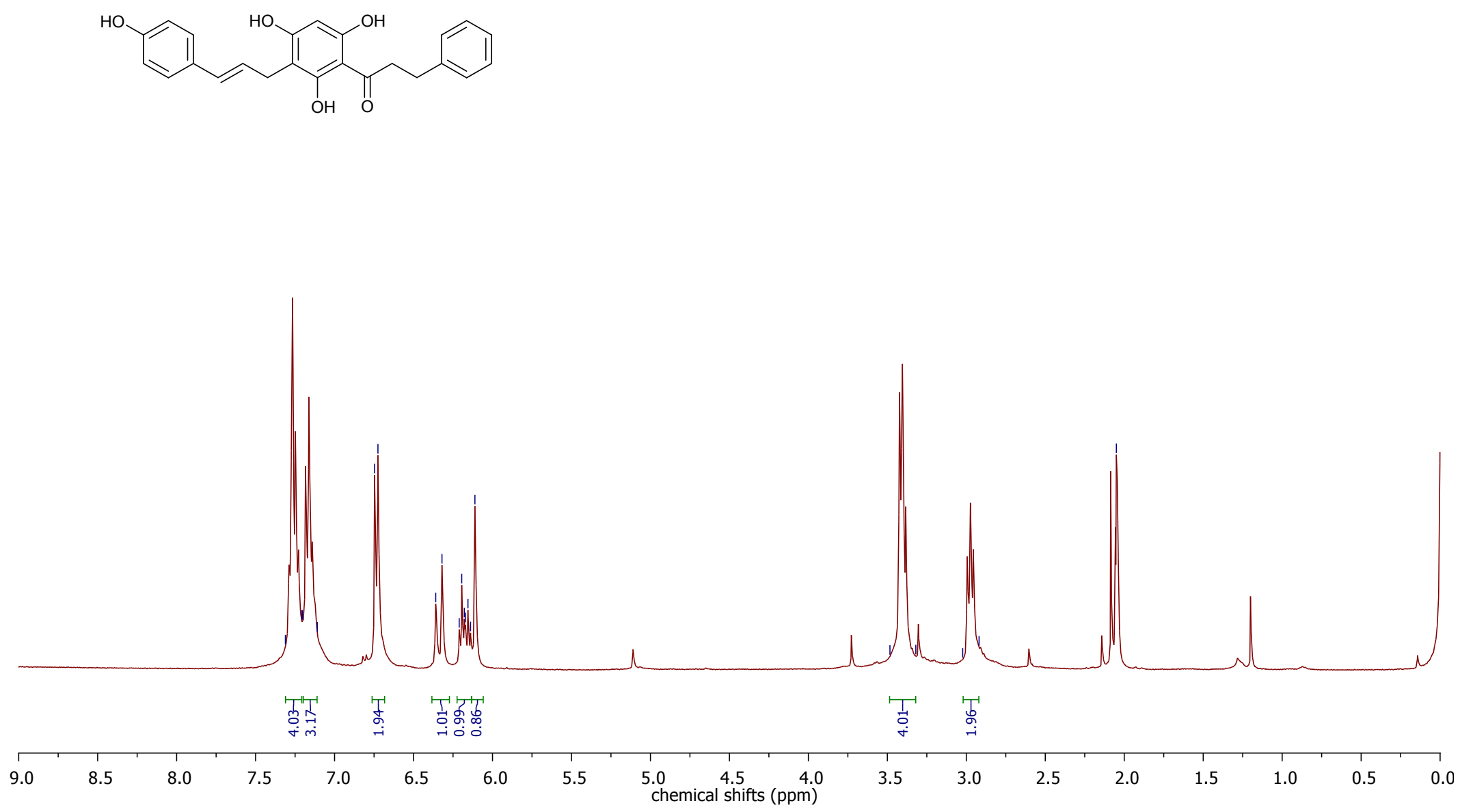
e. Figure S5: ${ }^{13} \mathrm{C}$ NMR spectrum of balsacone C (1c)

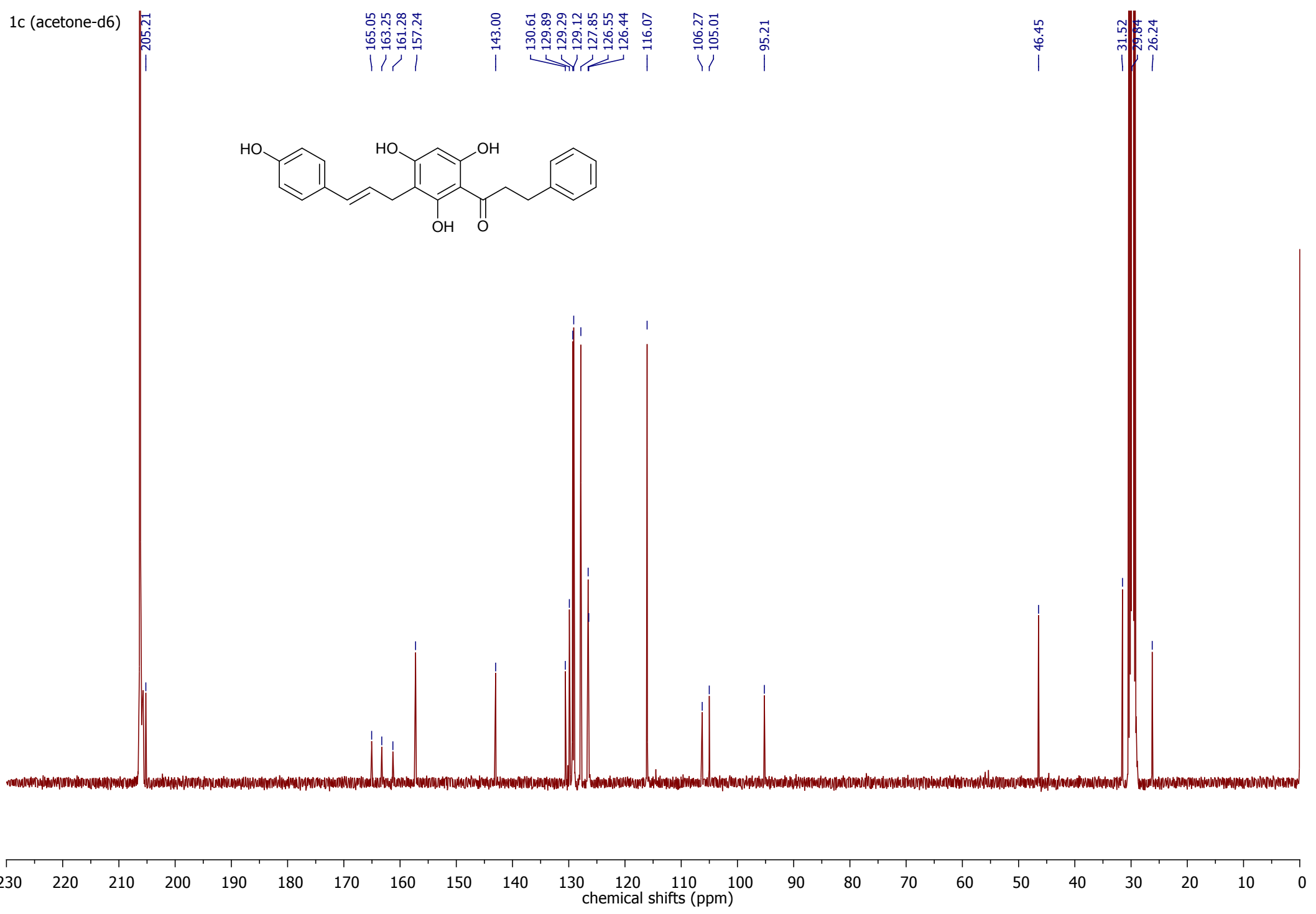




\section{f. Figure S6: ${ }^{1} H$ NMR spectrum of compound 1 d}

1d (acetonẹe-d6)

$\stackrel{+1}{1}$

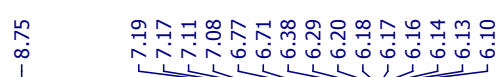

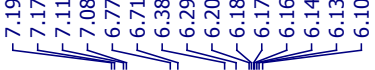

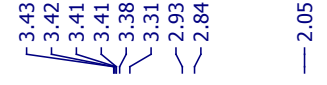
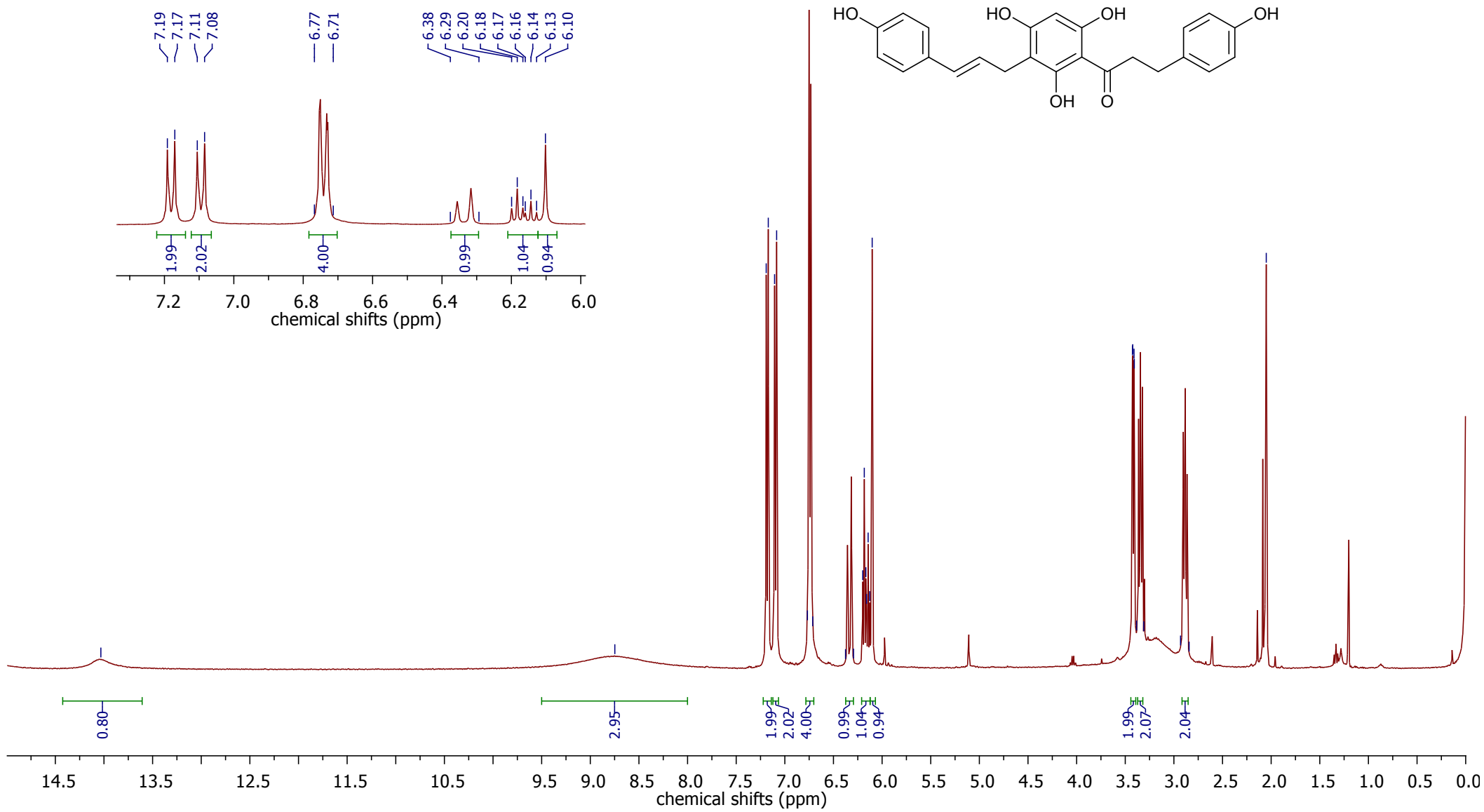
g. Figure S7: ${ }^{13}$ C NMR spectrum of compound $1 \mathbf{1 d}$

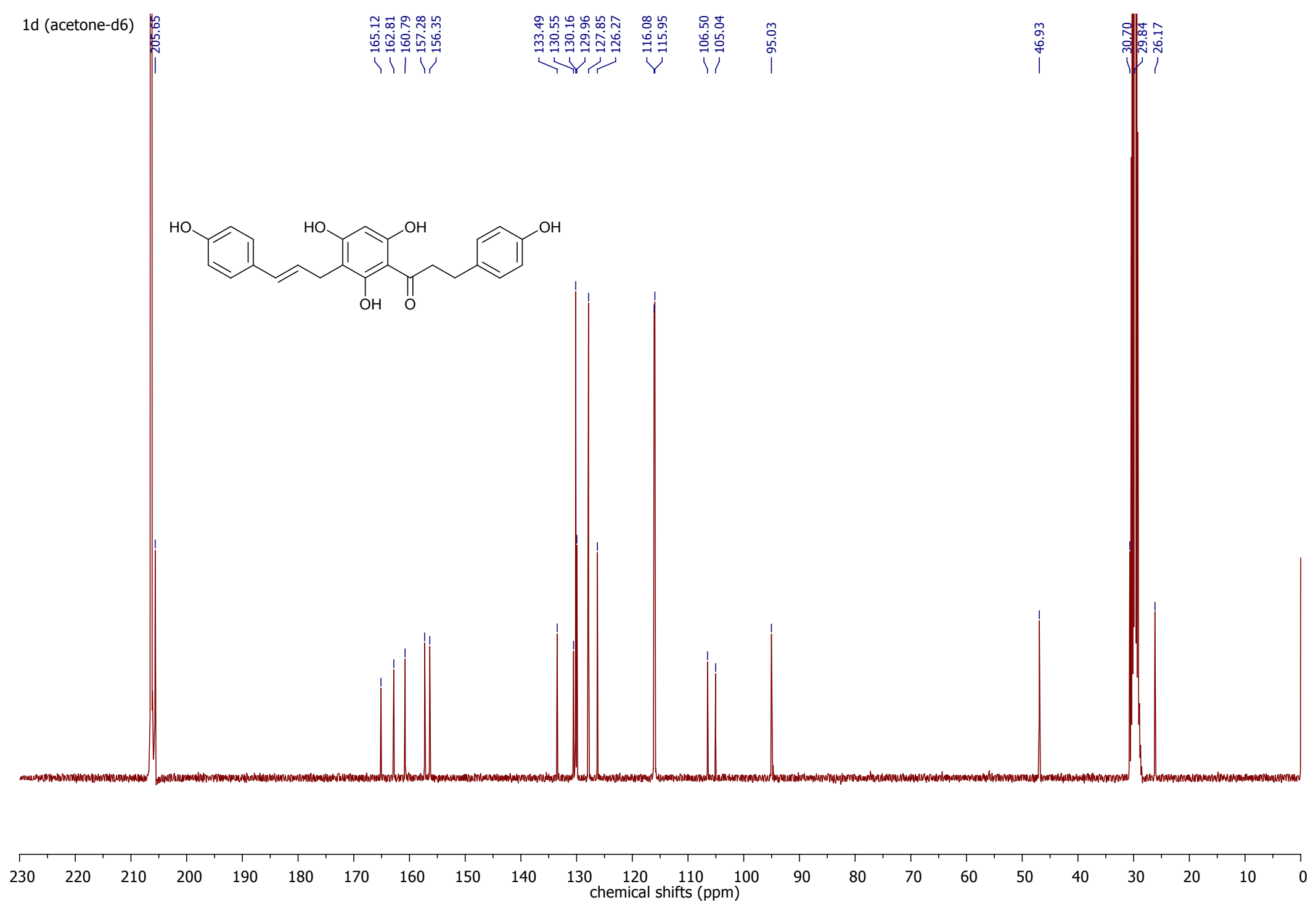


h. Figure S8: ${ }^{1} H$ NMR spectrum of compound $1 e$

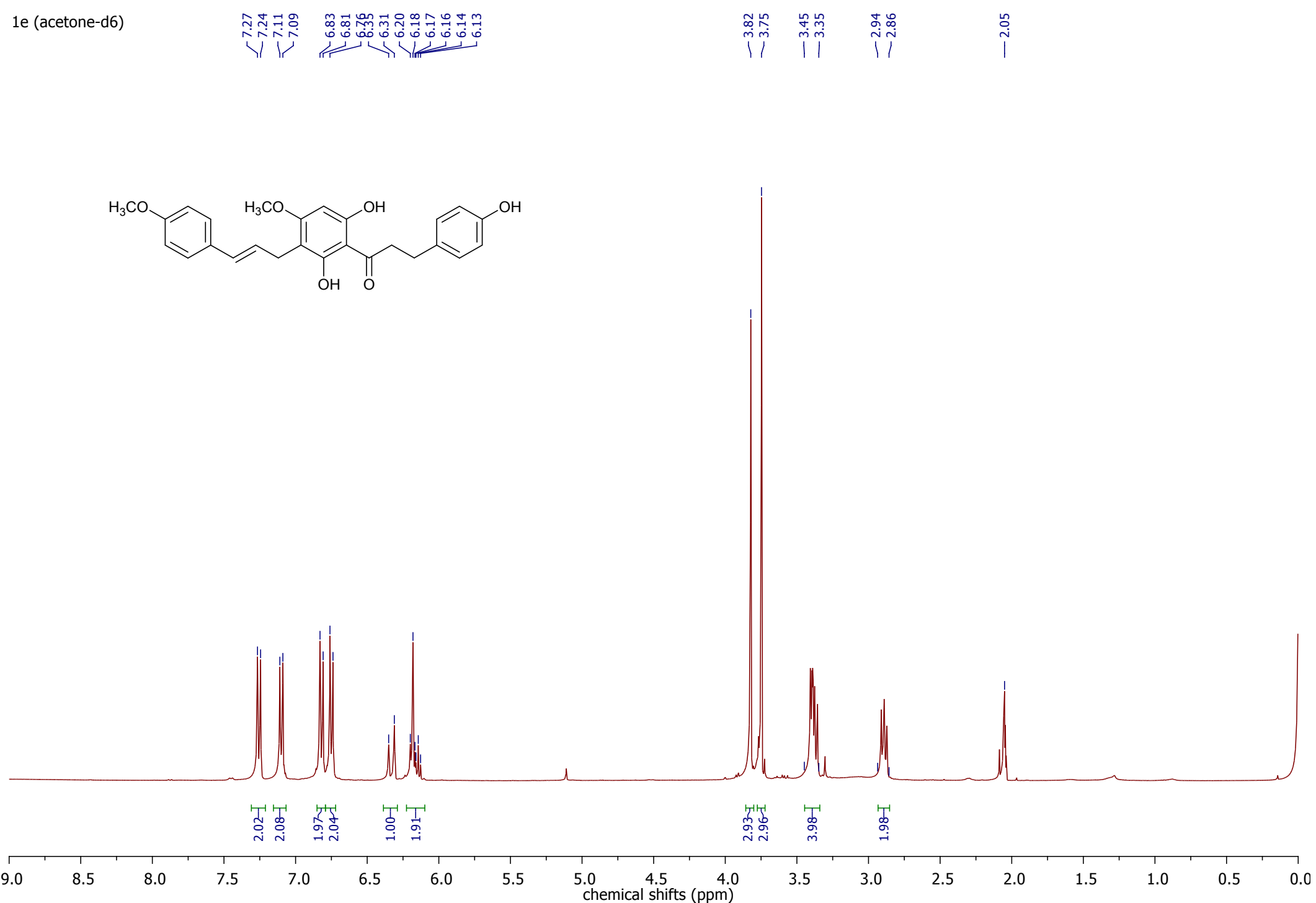


i. Figure S9: ${ }^{13} \mathrm{C}$ NMR spectrum of compound $1 \boldsymbol{e}$
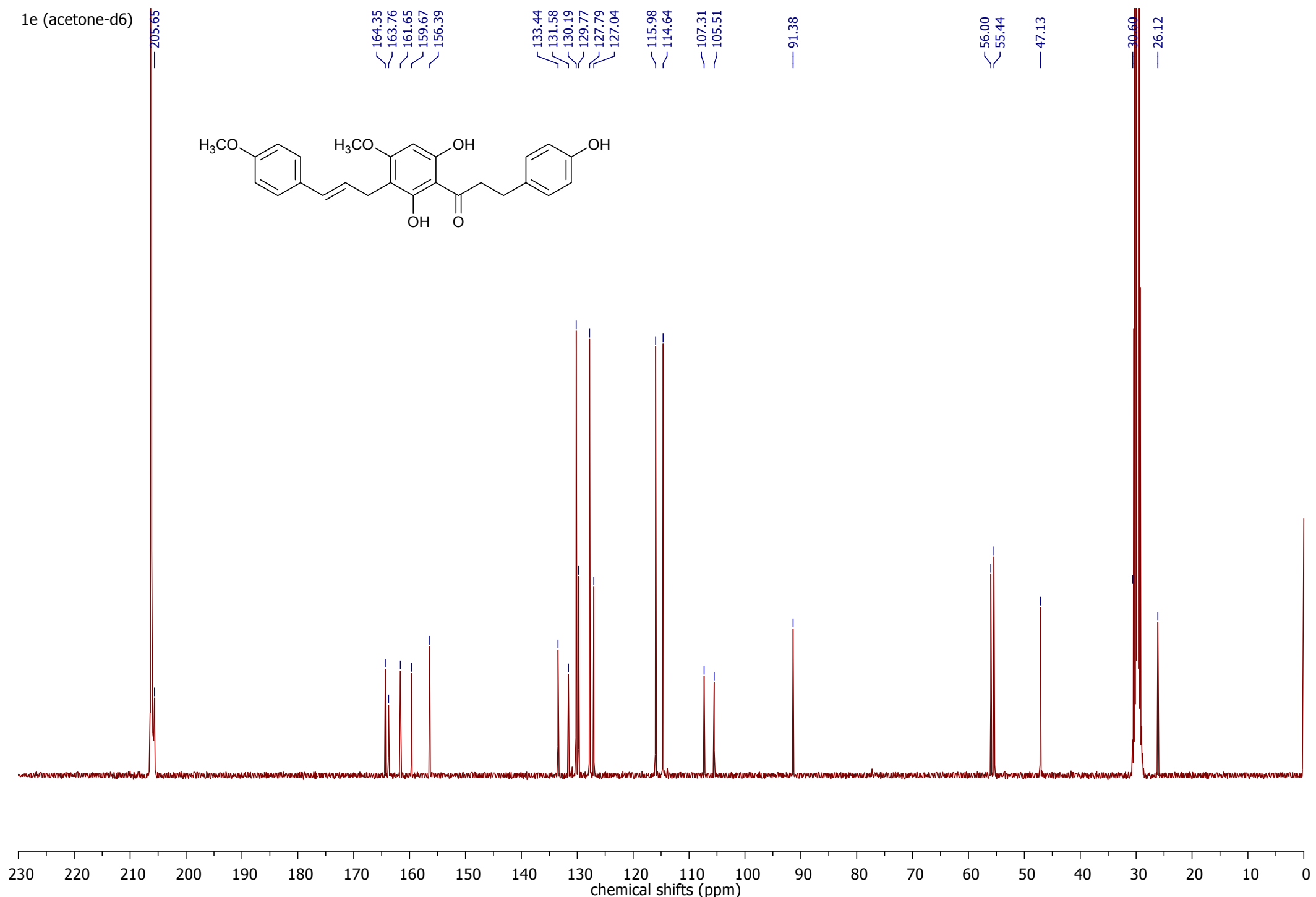
j. Figure S10: ${ }^{1} H$ NMR spectrum of compound $1 f$

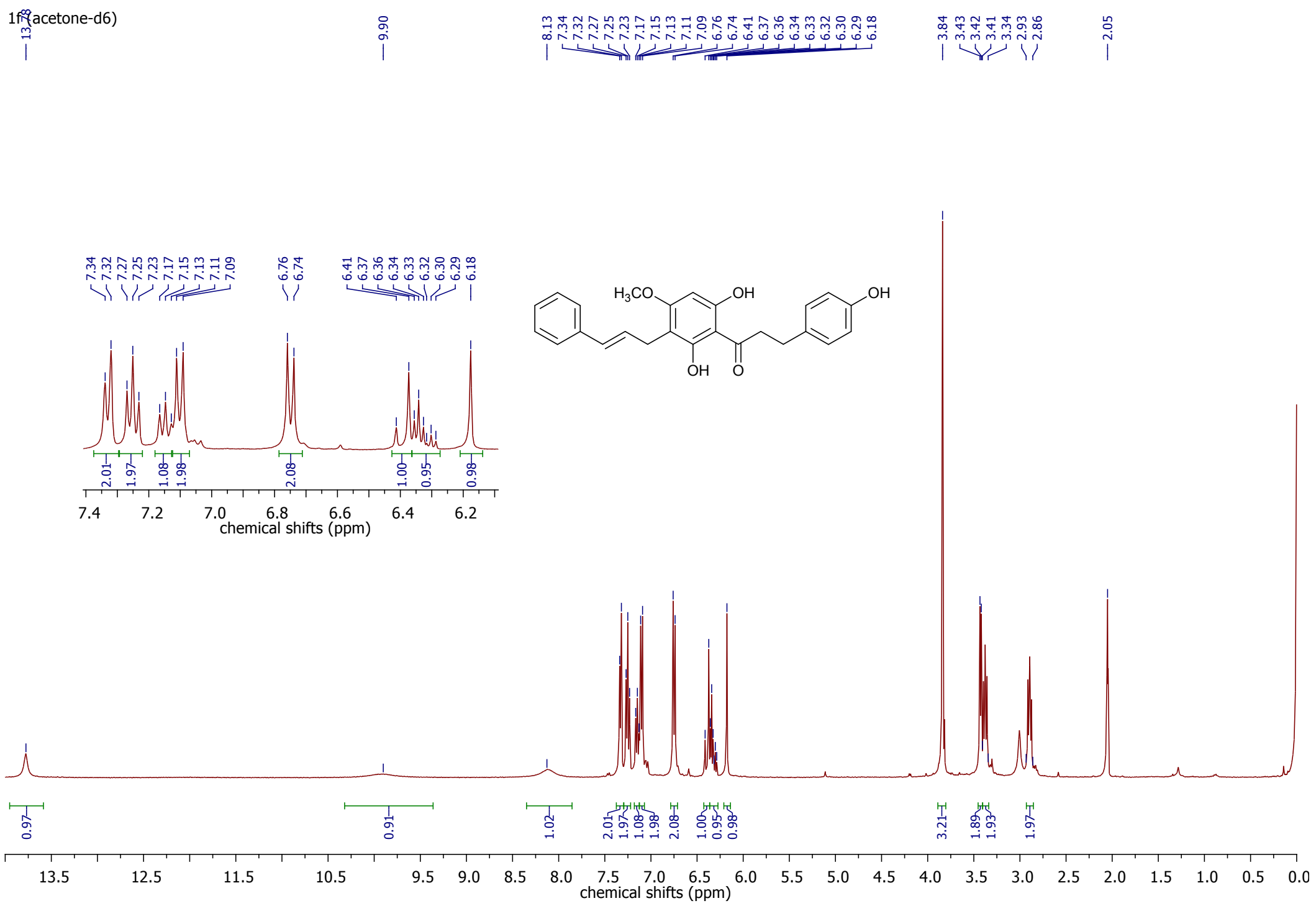


l. Figure S12: ${ }^{1} H$ NMR spectrum of compound $1 \mathbf{g}$

1g (MeOD)

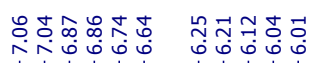

iरण,

ทึ่
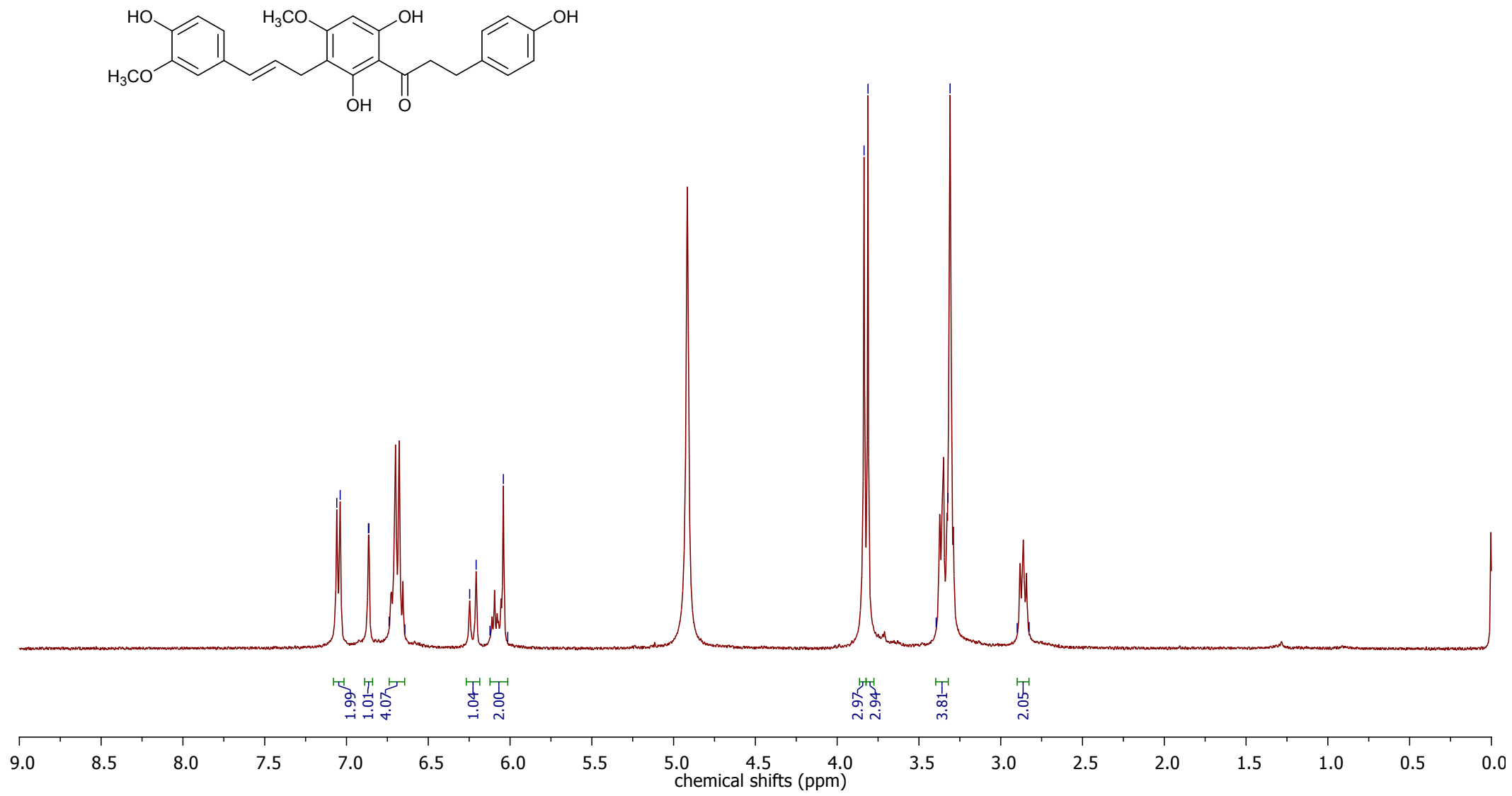
m. Figure S13: ${ }^{13} \mathrm{C}$ NMR spectrum of compound $\mathbf{1 g}$

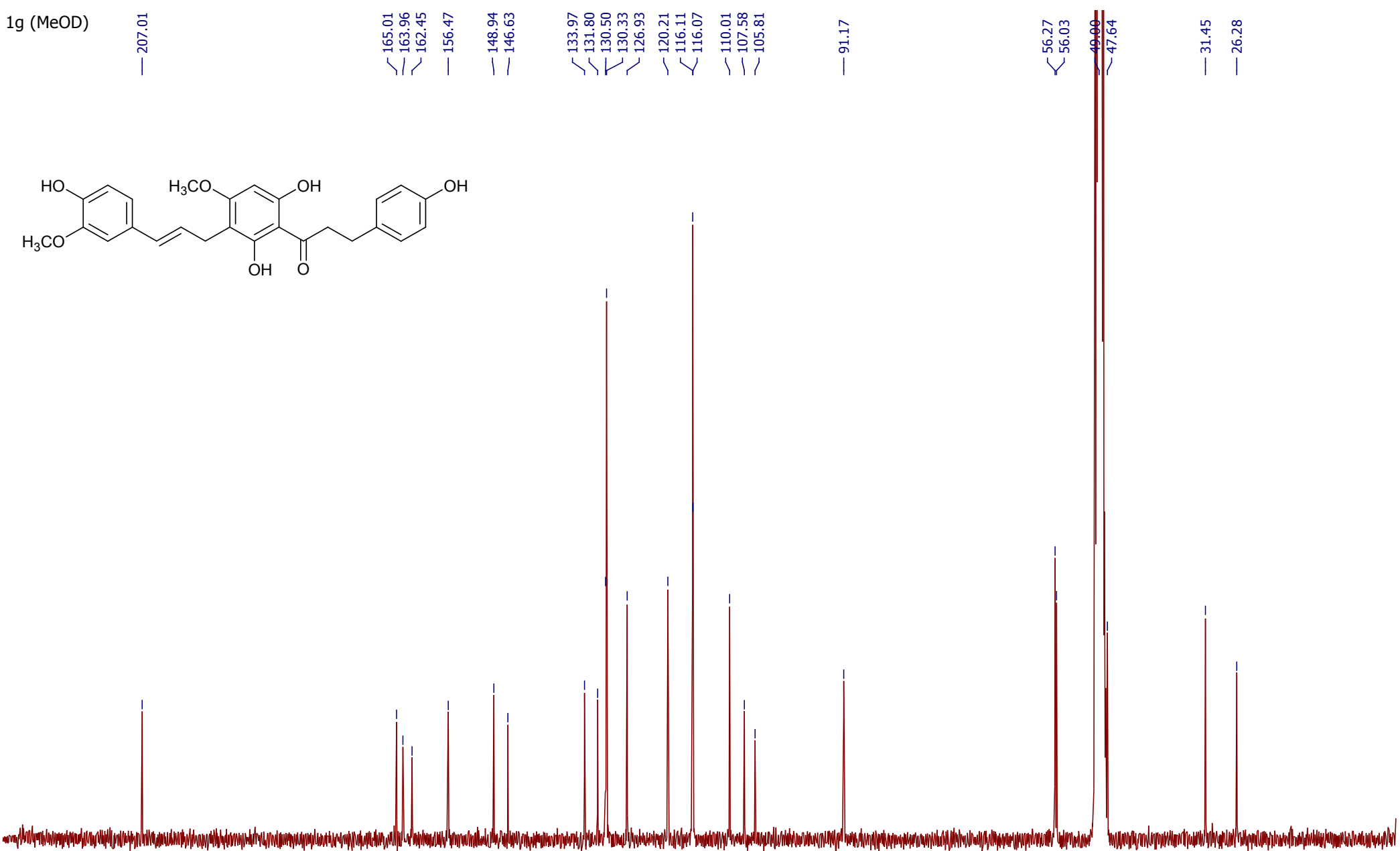

\begin{tabular}{rlllllllllllllllllllllll}
\hline 230 & 220 & 210 & 200 & 190 & 180 & 170 & 160 & 150 & 140 & $130 \begin{array}{c}120 \\
\text { chemical shifts (ppm) }\end{array}$ & 90 & 80 & 70 & 60 & 50 & 40 & 30 & 20 & 10 & 0
\end{tabular}


n. Figure S14: ${ }^{1} H$ NMR spectrum of compound 4

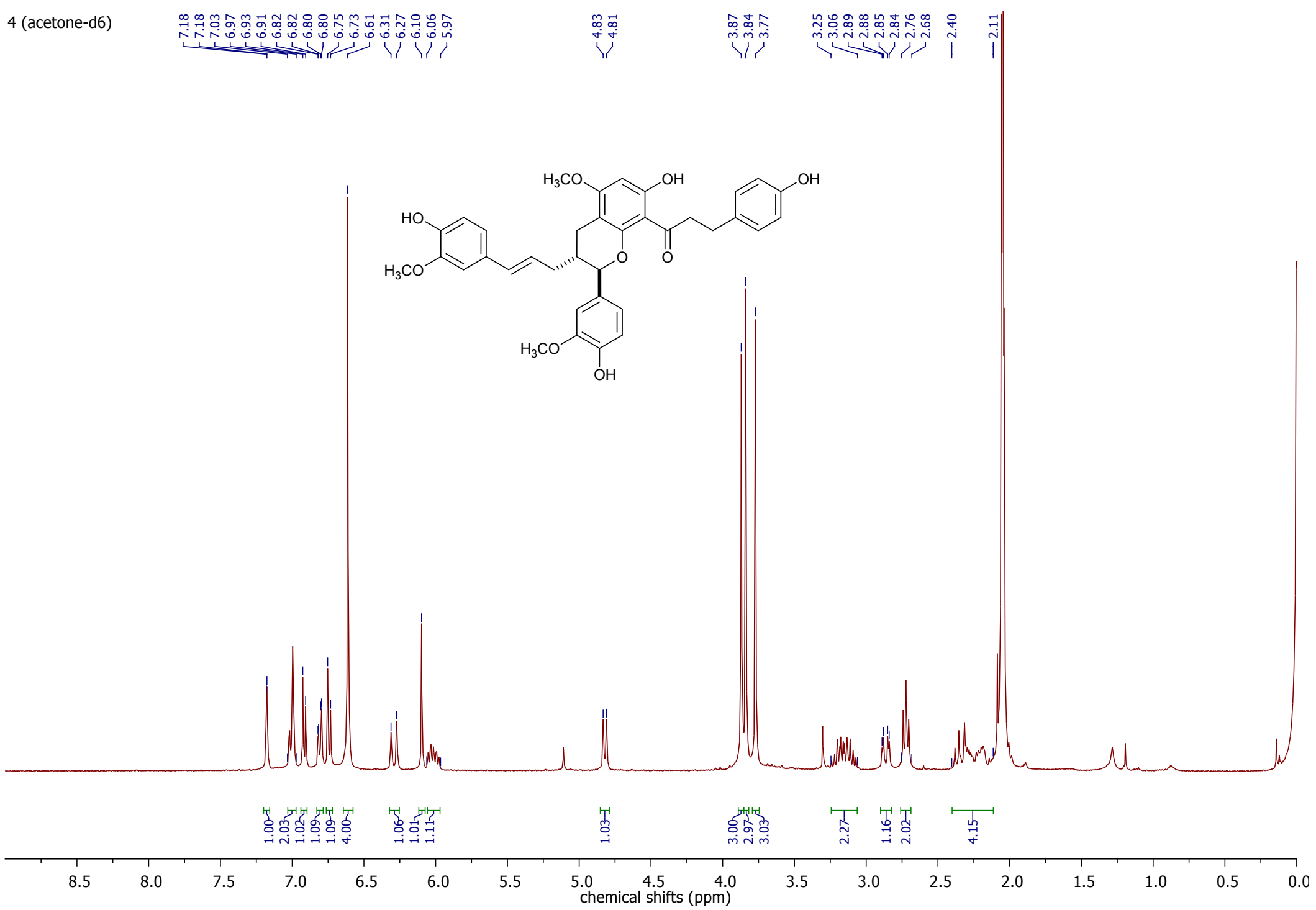


o. Figure S15: ${ }^{13} \mathrm{C}$ NMR spectrum of compound 4

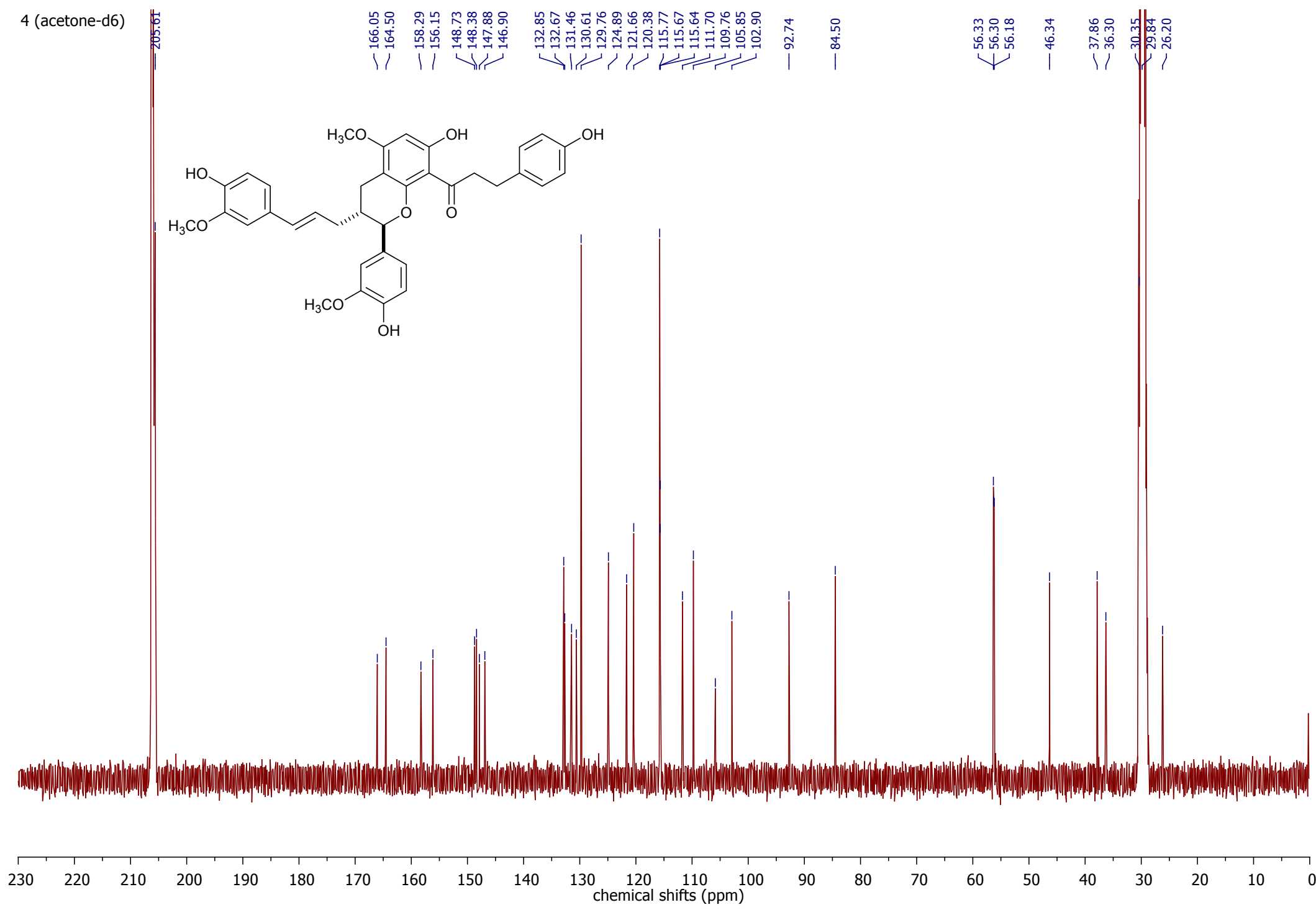

